Chapter 7

\title{
Treatment-Resistant Obsessive-Compulsive Disorder (OCD) - Current Understanding
}

\author{
Mushtaq A. Margoob, Rajesh Chandel, \\ Huda Mushtaq and Dhuha Mushtaq \\ Additional information is available at the end of the chapter \\ http://dx.doi.org/10.5772/57232
}

\section{Introduction}

Obsessive-compulsive disorder (OCD) is a chronic condition represented by a diverse group of symptoms that include intrusive thoughts, rituals, preoccupations, and compulsions. These recurrent obsessions or compulsions cause severe distress to the person. The obsessions or compulsions are time-consuming and interfere significantly with the person's normal routine, occupational functioning, usual social activities, or relationships [1].

In the 10th revision of International Statistical Classification of Diseases and Related Health Problems (ICD-10), OCD is diagnosed when either obsessions or compulsions (or both) are present for a period of at least 2 weeks, acknowledged as excessive or unreasonable and are repetitive and unpleasant. The patient tries to resist them and acknowledges that they are originating in the mind and are not imposed by outside persons or influences as well as the obsessive thought or the compulsive act is not experienced as pleasurable. [2] Recently American Psychiatric Association's (APA) Diagnostic and Statistical Manual of Mental Disorders, DSM-5 separated it from anxiety disorder group and reclassified it with disorders like Body Dysmorphic Disorder, Hoarding Disorder, Trichotillomania, and excoriation disorder [3].

A few decades ago OCD had been regarded as a psychiatric condition that was mostly treatment-refractory [4]. Modern pharmacotherapy for OCD began with the observation that colmipramine but not other TCAs, relieved OC symptoms. This led to hypothesis that serotonin might be involved in pathophysiology of OCD5. Also numerous investigations showing the therapeutic action of different selective serotonin reuptake inhibitors (SSRIs) in OCD, and by additional findings, such as the provocation of OCD symptoms by the seroto- 
nergic agent m-chlorophenylpiperazine the role of serotonergic system in OCD was further made strong. Not only is serotonin uptake blockade an apparent prerequisite for clinical improvement, but there is a correlation between the magnitude of clinical response and the reduction in various serotonin markers during treatment with these drugs [6]. There is substantial evidence that suggests OCD patients may benefit from addition of antipsychotics to their ongoing SSRI treatment, suggesting that dopamine also might play a role in the pathophysiology of OCD [7]. Latest neuroimaging techniques have shown various structural and volumetric abnormalities in prefrontal and basal ganglia region in patients suffering from OCD. In prefrontal cortex there may be dopaminergic hyperfunction and in basal ganglia there may be hypofunction of serotonergic system. This dysfunction of the 'cortico-striato-thalamic' loops is strongly linked to the symptoms of $\mathrm{OCD}$, where the dopamine has an inhibitory effect on GABA neurons. The ascending serotonergic projections from the raphe nuclei restrain and control the function of these loops. Thus, when serotonergic hypofunction is present, the predominantly dopaminergic loops became overactive, which has been confirmed by neuroimaging techniques and by neurocognitive tests as well. This could be the reason for the fact that SSRIs have limited success in the treatment of OCD symptoms [8]. The role of glutamate, which is the primary excitatory neurotransmitter, is being increasingly investigated in the pathophisiology of OCD [9]. Glutamate is major excitatory neurotransmitter in the corticostriatal-pallido-thalamocortical circuits and is also known to interact extensively with serotonin and dopamine [10]. Moore et al. (1998) reported striking changes in caudate glutamatergic concentrations (Glx)-a marker for combined glutamate and glutamine, resonance on proton magnetic resonance spectroscopy (1H-MRS) in a paediatric OCD patient following treatment with Paroxetine [11]. Rosenberg et al. (2000) studied 11 psychotropic drug-naïve children with OCD, with single-voxel 1H-MRS examinations and demonstrated that caudate Glx concentrations were significantly greater in the patients compared to healthy controls [12]. They also found that the caudate Glx levels in patients decreased significantly following 12-weeks treatment with Paroxetine to levels comparable to that of controls and the decrease was associated with decrease in symptom severity of the OCD patients, while there was no difference in Glx levels in the occipital cortex between the two groups. Whiteside et al. (2006) have demonstrated that within the right orbitofrontal white matter, relative levels of Glx and $\mathrm{N}$-acetylaspartate were increased in adult patients with OCD compared with healthy controls and greater levels of Glx/Creatine were associated with more severe OCD symptoms. [13] Evidences from genetic studies are also suggesting the role of glutamate in pathophsiology of OCD. Investigators have reported statistically significant association between OCD and a locus on chromosome 9p24 that codes for a high-affinity neuronal/epithelial excitatory amino acid transporter (EAAC-1), also known as SLC1A1 (Solute carrier family 1, member 1) [14, 15]. It is hypothesized that in the brain this transporter is crucial in terminating the action of the excitatory neurotransmitter glutamate and in maintaining extracellular glutamate concentrations within a normal range [16].Researchers have examined the role of the opioid system and neuropeptides like oxytocin and vasopressin in OCD although the evidence has been equivocal $[17,18,19]$.

About $40-60 \%$ of obsessive compulsive disorder (OCD) sufferers do not respond to appropriate courses of treatment with serotonin reuptake inhibitors (SRI) and even to combination of 
medicines [20]. Those OCD patients who do not achieve a satisfactory response after an adequate trial of first line therapies are described as treatment resistant. The satisfactory response is usually defined by a reduction in the Yale-Brown Obsessive Compulsive scale score $\geq 35 \%$ or $\geq 25 \%$ with respect to baseline [21].

The first selective serotonin reuptake inhibitor (SSRI), fluoxetine, was introduced in 1987. This was followed by other SSRI's i.e.fluvoxamine, paroxetine, sertraline, citalopram and escitalopram. The SSRIs are each structurally and chemically distinct. Escitalopram, an isomer of citalopram, is the only exception. This molecular diversity explains why individual responses to, and tolerability of, SSRIs are so varied. Fluoxetine has the longest half-life: 4 to 6 days. The half-life of sertraline is 26 hours, 35 hours for citalopram, 27 to 32 hours for escitalopram, 21 hours for paroxetine, and 15 hours for fluvoxamine. Sertraline, fluoxetine, and paroxetine being the most highly bound and escitalopram being the least bound. All SSRIs are metabolized in the liver by the cytochrome P450 enzymes. The most important drug-drug interactions involving the SSRIs occur as a result of the SSRIs inhibiting the metabolism of a co administered medication [1]. Citalopram and escitalopram are the most selective inhibitors of serotonin reuptake, with very little inhibition of norepinephrine or dopamine reuptake and very low affinities for histamine $\mathrm{H}_{1}$, GABA or benzodiazepine receptors. The other SSRIs have a similar profile, except that fluoxetine weakly inhibits norepinephrine reuptake and binds to $5-\mathrm{HT}_{2} \mathrm{C}$ receptors; sertraline weakly inhibits norepinephrine and dopamine reuptake; and paroxetine has significant anticholinergic activity at higher dosages and binds to nitric oxide synthase [1].

According to a large number of published randomized controlled trials (RCTs), meta-analyses, current expert guidelines, and consensus statements, SSRIs and clomipramine are recommended as first-line agents for drug treatment of $\operatorname{OCD}[22,23,24,25]$. Guidelines of the World Federation of Societies of Biological Psychiatry (WFSBP) for the pharmacological treatment of OCD grant the highest category of evidence (" $\mathrm{A}$ ", ie, full evidence from several RCTs) for the SSRIs escitalopram, fluvoxamine, fluoxetine, paroxetine, and sertraline, as well as for the TCA clomipramine. Since clomipramine is less well tolerated than the SSRIs, it was given a recommendation grade of 2 (moderate risk benefit ratio), while the SSRIs received the highest recommendation grade 1 (good risk: benefit ratio). For citalopram a recommendation grade of 3 (limited evidence from controlled studies) was given as only one positive double-blind, placebo-controlled study was published. According to WFSBP guidelines usually lower response rates are achieved in OCD in comparison with other anxiety disorders, and that sometimes only partial remission is achieved and higher doses are required for these drugs in OCD than for other anxiety disorders. In a systematic review of all long-term, placebocontrolled trials with SSRIs in OCD, the likelihood of relapse during 24 to 52 weeks of treatment was significantly lower on an SSRI than with placebo [26].

According to the British National Institute for Health and Clinical Excellence (NICE) and the Royal College of Psychiatrists guidelines, the initial pharmacological treatment in adults with OCD should be one of the following SSRIs: fluoxetine, fluvoxamine, paroxetine, sertraline, or citalopram [27]. A Cochrane review of placebo-controlled SSRI trials in OCD, comprising 17 studies with 3097 participants showed efficacy for all SSRIs (citalopram, fluoxetine, fluvoxa- 
mine, paroxetine, and sertraline) but no statistical differences in short-term therapeutic action among the individual SSRIs [28].

\section{Treatment of OCD patients refractory to serotonergic antidepressants}

Although SSRIs and clomipramine have proven efficacy in OCD, about $40 \%$ to $60 \%$ of patients show no or just partial symptom improvement to a treatment with a first-line drug [29]. The large fraction of patients without substantial response to standard treatment experiences significant morbidity [30]. Response is typically operationalized as a decline in symptoms, as measured by a 30-35\% reduction in the Yale-Brown Obsessive-Compulsive Scale (Y-BOCS) [31, 32] or a decline in symptoms below a threshold of 16 (i.e., the boundary between mild and moderate OCD symptoms). So those patients who are "treatment responsive" as per operationalized criterion may continue to have levels of symptoms in the mild-moderate range and spend hours daily preoccupied with their obsessions and compulsions. We need novel treatment modalities for these partially responsive as well as treatment resistant patients with OCD.

High-dose treatment with serotonergic drugs is one of the available strategy which should be considered first. Greater improvement with higher vs lower doses of SSRI was reported using 250 to $400 \mathrm{mg} / \mathrm{d}$ vs $200 \mathrm{mg} / \mathrm{d}$ of sertraline [33] and with escitalopram after an increase of dose from $20 \mathrm{up}$ to $50 \mathrm{mg} / \mathrm{d}$ [34]. In a Open-label study of high (30 mg) and moderate (20 mg) dose escitalopram for the treatment of obsessive-compulsive disorder by Dougherty et al found that the $30 \mathrm{mg}$ (vs. $20 \mathrm{mg}$ ) dose of escitalopram may provide a superior reduction in OCD symptoms for those sufferers with comorbid depression and/or anxiety [35].

Studies with tricyclic antidepressants, which act on both serotonin and norepinephrine, suggested that blockade of serotonin reuptake was required for antiobsessional effect [36]. In a meta-analysis of studies by Geller et al., including over 1000 adolescents with OCD clomipramine was shown to have greater efficacy compared with fluoxetine, fluvoxamine, paroxetine, and sertraline [37]. Clomipramine, which retains some norepinephrine reuptake inhibitory (NRI) effect relative to the SSRIs and its metabolite desmethylclomipramine has significant NRI activity, appears to be more effective than the more selective agents in meta analyses, though not in head-to-head comparisons leads to the hypothesis that dual-acting agent might be more effective in treatment- resistant patients [38]. An open-label trial of venlafaxine, which is a dual acting agent, both in treatment- naive and treatment-resistant OCD, suggested superior efficacy to SSRIs [39], In a head-to-head comparison between venlafaxine and clomipramine suggested comparable efficacy to clomipramine. [40]

Another strategy is to use other agents that target the serotonin system in a different way. Mirtazapine, a 5HT2A agonist, can accelerate the effect of paroxetine on OCD symptoms [41]. But the long-term benefit of mirtazepine and citalopram augumentation over citalopram alone is unclear [42]. Mirtazapine has also been shown to be efficacious as monotherapy in OCD patients in an open trial [43].

Intravenous clomipramine [44, 45] and intravenous citalopram [46] have been shown to lead to a substantial improvement in symptoms in some treatment-resistant patients. 


\section{Augmentation with other drugs}

A number of different agents are being used as augmentation strategies for standard SRI therapy in treatment- refractory OCD, with variable success. Agents with modes of action beyond the serotonin system have shown the capacity to significantly improve symptoms in patients with limited response to SRI therapy alone [47].

Tourette's syndrome is highly comorbid with Obsessive-compulsive disorder in the pediatric population [48]. Overlapping pathological changes in the basal ganglia are implicated in the two disorders $[49,50]$. As we see both typical and atypical antipsychotics have positive effects in Tourette's syndrometrials of dopamine antagonists, augmentation therapy in OCD might be worth considering [51,52].

The combination of the antipsychotics risperidone, haloperidol, olanzapine, or quetiapine with an SSRI was shown to be more effective than SSRI monotherapy in treatment-resistant cases and is recommended (grade 3, ie, limited evidence from controlled studies) by the WFSBP guidelines [25]. Antipsychotics should be added after at least 3 months of maximally tolerated therapy of an SSRI. Response usually commences within one month duration as seen in most of the studies and about one third of treatment-refractory OCD patients show a clinically meaningful improvement. Superior effects of quetiapine versus ziprasidone as an adjunct to SSRI were found in treatment-resistant OCD patients in a retrospective study [53]. A singleblind study comparing risperidone versus olanzapine augmentation of SSRIs showed positive responses without differences between the two treatment groups [54]. In a 12-week, openlabel, trial of aripiprazole, significant improvement of OCD symptoms was demonstrated [55]. In a small, open-label study suggest that aripiprazole as monotherapy was helpful for treating OCD [56].Augmentation of paroxetine with perospirone resulted in improvement in a case report [57].

A smaller number of studies have examined the utility of augmentation therapy with opioid agents. Morphine given once weekly has shown efficacy in treatment-resistant obsessivecompulsive disorder in a single doubleblind study, and administration of the opioid agonist tramadol hydrochloride has also been shown to diminish OCD symptoms [58, 59, 60].The mechanism of this interesting effect is unknown, but one of the proposed mechanism being opioids inhibiting glutamate release in cortex through disinhibition of serotonergic neurons.

Other augmentation agents include clonazepam, inositol, clonidine, monoamine oxidase inhibitors, and antiandrogens [61].

Positive results have been reported with longterm augmentation with citalopram (up to 60 $\mathrm{mg} / \mathrm{d}$ ) in 20 treatment-resistent OCD patients on clomipramine [62].

Riluzole is an antiglutamatergic agent that is approved by the Food and Drug Administration for neuroprotection in amyotrophic lateral sclerosis (ALS) [63]. Various proposed mechanisms of action of riluzole are inhibition of sodium currents in glutamatergic axon terminals, reducing neurotransmitter release [64]; reduction of P/Qtype calcium currents in the axon terminals, with a similar effect on glutamate release [65]; extension of the open time of Kv1.4 potassium 
channels [66]; and increased astrocytic uptake of glutamate [67]. A case report and an open label study suggest augmentation with the antiglutamatergic agent riluzole in SRI-resistant OCD patients has significant efficacy $[68,69]$.

The amino acid N-acetylcysteine (NAC) is widely used for its antioxidant properties and as an antidote for acetaminophen toxicity. Preclinical studies suggest that NAC also modulates CNS glutamate. NAC is converted to cystine, a substrate for the glutamate/ cystine antiporter located on glial cells. The uptake of cystine by glia causes glial release of glutamate into the extrasynaptic space, where it appears to stimulate inhibitory metabotropic glutamate receptors on glutamatergic nerve terminals and thereby reduces the synaptic release of glutamate [70].There is evidence for benefit of NAC augmentation to SSRI's in treating SRI-refractory OCD in two preliminary case reports [71, 72].

In an open-label augmentation trial with memantine, an N-methyl-Daspartate (NMDA) glutamate receptor antagonist, improvement of symptoms was seen in about half of the patients, who had failed to respond to treatment with an SSRI for at least 3 months [73]. Feusner et al in 2009 in an open label trial, compared the differential efficacy of memantine for obsessive-compulsive disorder vs. generalized anxiety disorder. Ten OCD and 7 GAD subjects received 12 weeks of open-label memantine $10 \mathrm{mg}$ twice daily, as either monotherapy or augmentation of their existing medication. Primary outcome measures were the Yale-Brown Obsessive Compulsive Scale ( YBOCS) for the OCD group, the Hamilton Anxiety Rating Scale (HARS) for the GAD group, and the Clinical Global Impression-Improvement Scale (CGII) for both groups. The results suggest that memantine may have preferential efficacy in the treatment of OCD versus GAD. But further larger placebo controlled studies are required [74].A Single-Blinded Case-Control Study of Memantine in Severe Obsessive-Compulsive Disorder provides preliminary supportive evidence for the effectiveness of memantine as a glutamatergic augmenting agent in severe OCD [75].

Adjunctive glycine (an NMDA glutamate receptor agonist) was also tested in a small doubleblind placebo-controlled trial and approached efficacy for treatment of OCD symptoms but with high dropout rates [76].

Amantadine (another NMDA antagonist) could be a useful drug for the treatment of OCD according to preclinical findings [77].

Augmentation of SSRI's with topiramate, in treatment-resistant OCD patients may be beneficial $[78,79]$. Double-blind studies with topiramate are being conducted [80].

Pregabalin, which can indirectly inhibit glutamate release via blockade of calcium channels, beneficial effects on OCD symptoms in combination with serotonergic antidepressants have been reported in case reports [81, 82].A double-blind placebo-controlled study with pregablin in SSRI-refractory OCD is being conducted [83].

D-cycloserine (a glutamatergic partial N-methyl-d-aspartate (NMDA) agonist) augmentation of psychotherapy with exposure and response prevention in OCD has so far been investigated in three randomized, double-blind, placebo-controlled studies. Significantly greater decreases in obsession-related distress after four exposure sessions under D-cycloserine (125 mg, given 
2 hours before each session) were reported, however, after additional sessions, the placebo group tended to catch up [84]. In another study, OCD patients were reported to be significantly more improved under D-cycloserine at mid-treatment (ten behavior therapy sessions in total, dose of $100 \mathrm{mg} 1$ hour before each session), but not at later time points, and the ${ }_{\mathrm{D}}$-cycloserine group's depressive symptoms were significantly more improved at posttreatment [85].

In a randomized, double-blinded, placebo-controlled augmentation trial examining CBT $+\mathrm{D}$ cycloserine versus CBT + Placebo with 30 youth (aged 8-17) with a primary diagnosis of OCD received seven exposure and response prevention sessions paired with DCS or placebo taken 1 hour before sessions. Compared with the CBT + Placebo group, youth in the CBT + D cycloserine arm showed small-to-moderate treatment effects. These results provide initial support for a more extensive study of D Cycloserine augmentation of CBT among youth with OCD [86].

It has been reported that canna-binoids inhibit glutamate release in the CNS. As discussed above glutamate is implicated in pathophisiology of OCD. Addition-ally, cannabinoid type 1 (CB1) receptors are distributed abun-dantly in the striatum, a brain region frequently associated with OCD $[87,88]$.

Two case reports showed Improvement in Refractory Obsessive Compulsive Disorder With cannabinoid Dronabinol [89].

\section{Augmentation with or switch to cognitive-behavioral psychotherapy}

In a RCT, patients who were put on adequate dosages of SSRI for at least 12 weeks, and in those who continued to have clinically significant symptoms, the augmentative effect of exposure and ritual prevention versus stress management training was compared; Group with exposure and response prevention had significant decrease of symptom severity of at least $25 \%$ by the end of 8 weeks [90].In a controlled open trial, patients with a history of an inadequate response to multiple SSRI medications in adequate doses were treated with 15 sessions of outpatient CBT. OCD symptoms decreased significantly and gains were maintained over 6 months [91]. A meta-analysis of psychotherapy and pharmacotherapy for OCD found highest effect sizes for combined treatment [92].

\section{Invasive treatment options}

\subsection{Psychosurgery}

Treatment resistant obsessive-compulsive disorder is one of the few diagnoses in modern psychiatry for which invasive neurosurgical procedures are part of the established treatment options. All ablative neurosurgical techniques target the CSTC circuits that are believed to be hyperactive in OCD. Anterior cingulotomy involves a lesion targeting the anterior cingulated cortex and cingulum. Anterior capsulotomy targets the subcaudate white matter, interrupting 
frontothalamic fibers. Limbic leucotomy combines these two, lesioning both cingulum and subcaudate white matter [93].

\subsection{Deep brain stimulation}

Several small-scale controlled and open studies have suggested that deep brain stimulation (DBS) of the internal capsule and/or the adjacent ventral striatal region may be of benefit to severely affected OCD patients who have exhausted conventional therapies [94, 95, 96, 97, 98, 99, 100, 101].

Benjamin et al in 2006 found promising long-term effects of DBS in highly treatment-resistant OCD [102].

\subsection{Electroconvulsive therapy (ECT)}

Maletzky and colleagues in a retrospective study of 32 patients with treatmentresistant OCD who received ECT between 1979 and 1991 (19 non-depressed and 13 depressed; 14 were primarily checkers, 13 primarily cleaners, 4 did both). They were treated with bilateral frontotemporal ECT and were evaluated 2 days prior to the start of treatment and at 5 days, 6 months, and 12 months after treatment. Five days after treatment, there were highly significant differences between the pre- and post-scores (paired t-tests; $\mathrm{P}<.001$ ). At 6-months posttreatment, the differences were still significant. In this study, ECT had an anti-obsessional effect and the improvements occurred equally frequently and to an equal extent in depressed and non-depressed groups [103]. In addition, several single-case reports provided further evidence of the possible efficacy of ECT in treatment-resistant OCD. However, the unblinded design of these reports, the frequent comorbidity with other Axis I psychopathology (schizophrenia, depression, and Tourette's syndrome), and the different parameters of ECT used limit the confidence that can be placed in the findings [104, 105, [106, 107, 108].

\subsection{Repetitive transcranial magnetic stimulation (rTMS)}

Greenberg and colleagues randomized 12 patients with OCD into a singleblind trial. Patients were treated with 1 session of active right-side, active left-side, or sham (occipital position) TMS. Based on previous reports of prefrontal hypermetabolism or hyperperfusion in patients with OCD,44 Greenberg and colleagues believed that the application of a highfrequency rTMS to prefrontal cortex would have transiently interrupted OCD symptoms. The main finding was that right prefrontal rTMS had modest acute effects on compulsions whereas effects of left lateral prefrontal and occipital stimulation were transient and nonsignificant. Obsessions appeared unaffected by rTMS. Treatment was well-tolerated, with two patients reporting mild headache after stimulation [109]. Sachdev and colleagues randomized 12 treatment-resistant OCD patients to a 10-session, single-blind, 2-week trial of active right-side or left-side TMS. Ten subjects were taking medication (benzodiazepines, antidepressants, or antippsychotics) and had been maintained on a constant dose for 8 weeks prior to and during the period of the study. Evaluations after 2 weeks of stimulation and 1 month after the completion of the treatment showed significant reduction in obsessions and compulsions in both groups with 
no significant difference between right and left stimulation on the overall Y-BOCS score. The authors suggested that rTMS may be beneficial in the acute treatment of treatment resistant OCD with an equal proportion of patients benefiting from right- and left-sided stimulation [110]. In an open-label trial,10 patients with a history of several medication trial failures were treated for 2 weeks with low-frequency TMS. The supplementary motor area (SMA) was chosen as the site of stimulation with the coil placed along the sagittal midline in order to stimulate the SMA bilaterally and simultaneously. The sample had a significant general clinical improvement on the Clinical Global Impression Scale at the end of the first and second week of treatment, and maintained that benefit at 1 month and 3 month follow-up [111]. Chiara Ruffini and colleagues took twenty-three consecutively admitted right-handed inpatients with DSM-IV-TR-diagnosed drug-resistant OCD and gave rTMS to the left OFC parallel (active: $\mathrm{n}$ $=16$ ) or perpendicular (sham: $\mathrm{n}=7$ ) to the scalp. The patients' OCD symptoms, mood, and anxiety were rated at baseline, at the end of treatment, and once every 2 weeks for 3 months after treatment. Considering changes in Yale-Brown Obsessive Compulsive Scale (YBOCS) scores with 2-way analysis of variance for repeated measures for a total of 8 observations (before rTMS, after treatment, and every 2 weeks for 12 weeks' follow-up), and found significant reduction of YBOCS scores comparing active versus sham treatment for 10 weeks after the end of rTMS $(\mathrm{P}<.02)$, with loss of significance after 12 weeks $(\mathrm{P}<.06)$. They concluded Lowfrequency rTMS of the left OFC produced significant but time-limited improvement in OCD patients compared to sham treatment [112]. In a Randomized sham-controlled trial of repetitive transcranial magnetic stimulation in treatment-resistant obsessive-compulsive disorder Antonio Mantovani et al found the response rate was 67\% (6/9) with active and 22\% (2/9) with sham rTMS after $4 \mathrm{wk}$ and patients receiving active rTMS showed on average a $25 \%$ reduction in the YBOCS compared to a $12 \%$ reduction in those receiving sham. In those who received 8wk active rTMS, OCD symptoms improved from $28.2 \pm 5.8$ to $14.5 \pm 3.6$ [113].

Albert et al(2013) have most recently extensively reviewed available data on treatment resistant OCD and attempted to build a treatment algorithm for those patients who fail to respond to a first SSRI trial [114].

As WHO considers OCD to be fourth major mental illness with significant morbidity we need more effective treatment options. Though a lot of research is available regarding evidence based treatment approaches in treatment refractory OCD, a lot of clinical mysteries are still present and further research need to be done. Most of the research available today is preliminary short duration studies with small sample size and we need long term clinical trials to further validate the hypothesis formed from these preliminary studies.

Serotonin related gene polymorphism is a field which might help in the prediction of response to serotonergic drugs. Denys et al found that response in venlafaxine-treated OCD patients is associated with the S/L genotype of the 5-HTTLPR polymorphism and in paroxetine-treated OCD patients with the G/G genotype of the 5-HT2A polymorphism [115].

Functional imaging techniques for glucose metabolism might also predict treatment response in patients with OCD. Saxena et al suggested that elevated activity (cerebral glucose metabolism) in the right caudate may be a marker of responsiveness to antiobsessional treatment [116]. 
Metabotropic glutamate receptor anatagonists, are being developed by pharmaceutical industry which might be of help in treatment resistant OCD patients $[117,118,119]$.

Some of this exciting research may soon get translated into relevant clinical treatment options for the patients suffering from continued agonizing symptoms of OCD.

\section{Author details}

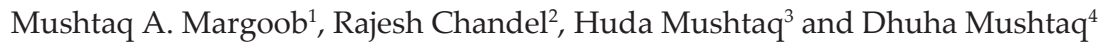

1 Department of Psychiatry, Institute of Mental Health and Neurosciences-Kashmir, India

2 Department of Psychiatry, Institute of Mental Health and Neurosciences-Kashmir, India

3 Behavioral Genetics and Neurobiology Research Laboratory, Institute of Mental Health and Neurosciences-Kashmir, India

4 Department of Psychiatry, Institute of Mental Health and Neurosciences-Kashmir, India

\section{References}

[1] Kaplan \& Sadock's Synopsis of Psychiatry: Behavioral Sciences/Clinical Psychiatry, 10th Edition.

[2] WHO's The ICD-10 Classification of Mental and Behavioral Disorders.

[3] Diagnostic and statistical manual of mental disorders, Fifth Edition.

[4] Michael Kellner, Drug treatment of obsessive-compulsive disorder, Dialogues Clin Neurosci. 2010 June; 12(2): 187-19.

[5] Textbook Of Anxiety Disorder/ DJ Stein APA 2nd edition.

[6] J Clin Psychiatry. 1990 Aug;51 Suppl:27-31; discussion 55-8. Neurobiology of obsessive compulsive disorder: a possible role for serotonin. Winslow JT, Insel TR.

[7] J Clin Psychiatry. 2004;65 Suppl 14:11-7. The role of dopamine in obsessive-compulsive disorder: preclinical and clinical evidence. Denys D, Zohar J, Westenberg HG.

[8] Psychiatr Hung. 2007;22(4):248-58.New approach to obsessive-compulsive disorder: dopaminergic theories; Harsányi A, Csigó K, Demeter G, Németh A.

[9] Bronstein Y, Cummings J. In: Lichter D, Cummings J Ed, Frontal-subcortical circuits inpsychiatric and neurological disorders. Guilford, New York. 2001; 59-91. 
[10] Rosenberg DR, MacMillan SN, Moore GJ. Brain anatomy and chemistry may predict treatment response in paediatric obsessive-compulsive disorder. Int J Neuropsychopharmacol 2001; 4(2): 179190.

[11] Moore GJ, MacMaster FP, Stewart C, Rosenberg DR. Case study: caudate glutamatergic changes with paroxetine therapy for pediatric obsessive-compulsive disorder. J Am Acad Child Adolesc Psychiatry 1998: 37(6): 663-67.

[12] Rosenberg DR, MacMaster FP, Keshavan MS, Fitzgerald KD, Stewart CM, Moore GJ. Decrease in caudate glutamatergic concentrations in pediatric obsessive-compulsive disorder patients taking paroxetine. J Am Acad Child Adolesc Psychiatry 2000; 39(9): 1096-103.

[13] Whiteside SP, Port JD, Deacon BJ, Abramowitz JS. A magnetic resonance spectroscopy investigation of obsessive-compulsive disorder and anxiety. Psychiatry Res 2006; 146(2): 137-47.

[14] Dickel DE, Veenstra-VanderWeele J, Cox NJ, et al. Association testing of the positional and functional candidate gene SLC1A1/EAAC1 in early-onset obsessive-compulsive disorder. Arch Gen Psychiatry 2006; 63(7): 778-85.

[15] Arnold PD, Sicard T, Burroughs E, Richter MA, Kennedy JL. Glutamate transporter gene SLC1A1 associated with obsessivecompulsive disorder. Arch Gen Psychiatry 2006; 63(7): 769-776.

[16] Leckman JF, Kim Y. A Primary candidate gene for obsessivecompulsive disorder. Arch Gen Psychiatry 2006; 63(7): 717-20.

[17] Keuler DJ, Altemus M, Michelson D, Greenberg B, Murphy DL. Behavioral effects of naloxone infusion in obsessive-compulsive disorder. Biol Psychiatry 1996; 40: 154-156.

[18] Altemus M, Pigott T, Kalogeras KT, Demitrack M, Dubbert B. Abnormalities in the regulation of vasopressin and corticotrophin releasing factor secretion in obsessivecompulsive disorder. Arch Gen Psychiatry 1992; 49: 9-20.

[19] Leckman JF, Goodman WK, North WG, et al. The role of central oxytocin in obsessive compulsive disorder and related normal behavior. Psychoneuroendocrinology 1994; 19(8): 723-49.

[20] Bhattacharyya S, Chakraborty K; Recent Pat CNS Drug Discov. 2007 Jan;2(1):47-55. Glutamatergic dysfunction--newer targets for anti-obsessional drugs.

[21] Rauch SL,JenikeMA(1994)Management of treatment resistant obsessive compulsive disorder: concepts and strategies. In Hollander E, Zohar J,Marazziti D, Olivieri B(eds) current insights in obsessive compulsive disorder,John Wiley and Sons Ltd, Chichester. 
[22] Stein DJ, Ipser JC, Baldwin DS, Bandelow B. Treatment of obsessive-compulsive disorder.. CNS Spectr. 2007;12(suppl 3):28-35.

[23] DS, Anderson IM, Nutt DJ, et al. Evidence-based guidelines for the pharmacological treatment of anxiety disorders: recommendations from the British Association for Psychopharmacology.. J Psychopharmacol. 2005;19:567-596.

[24] American Psychiatric Association: Practice guidelines for the treatment of patients with obsessive-compulsive disorder.. Am J Psychiatry. 2007;164 (suppl 1):1-56.

[25] W B, Zohar J, Hollander E, et al. World federation of societies of biological psychiatry (WFSBP) guidelines for the pharmacological treatment of anxiety, obsessive-compulsive and post-traumatic stress disorders first revision.. W J Biol Psychiatry. 2008;9:248-312.

[26] NA, Pampaloni I, Pallanti S, Ipser J, Stein DJ. Sustained response versus relapse: the pharmacotherapeutic goal for obsessive-compulsive disorder.. Int Clin Psychopharmacol. 2007;22:313-322.

[27] NICE clinical guideline 31 Obsessive-compulsive disorder: core interventions in the treatment of obsessive-compulsive disorder and body dysmorphic disorder.. 2005 Available at: www. Nice.org.uk.

[28] GM, Altmann DG, Rajagopal S, Oakley-Browne M. Selective serotonin re-uptake inhibitors (SSRIs) versus placebo for obsessive compulsive disorder (OCD).. Cochrane Database Syst Rev. 2008;1.

[29] McDougle CJ, Goodman WK, Leckman JF, Price LH. The psychopharmacology of obsessive-compulsive disorder implications for treatment and pathogenesis.. Psychiatr Clin North Am. 1993;16:749-766.

[30] Hollander E, Kwon JH, Stein DJ, Broatch J, Rowland CT, Himelein CA. Obsessivecompulsive and spectrum disorders: overview and quality of life issues. J Clin Psychol 57:3-6, 1996.

[31] Goodman WK, Price LH, Rasmussen SA, Mazure C, Fleischmann RL, Hill CL, Heninger GR, Charney DS. The Yale-Brown obsessive compulsive scale. I. Development, use, and reliability. Arch Gen Psych 46:1106 -1111, 1989.

[32] Goodman WK, Price LH, Rasmussen SA, Mazure C, Delgado P, Heninger GR, Charney DS. The Yale-Brown obsessive compulsive scale. II. Validity. Arch Gen Psych 46:1012-1016, 1989.

[33] Ninan pT, Koran LM, Kiev A, et al. High-dose sertraline strategy for nonresponders to acute treatment for obsessive-compulsive disorder: a multicenter double-blind trial.. J Clin Psychiatry. 2006;67:15-22.

[34] Rabinowitz I Baruch Y, Barak Y. High-dose escitalopram for the treatment of obsessive-compulsive disorder.. Int Clin Psychopharmacol. 2008;32:49-53. 
[35] Dougherty DD, Jameson M, Deckersbach T, Loh R, Thompson-Hollands J, Jenike M, Keuthen NJ. Open-label study of high $(30 \mathrm{mg})$ and moderate $(20 \mathrm{mg})$ dose escitalopram for the treatment of obsessive-compulsive disorder. Int Clin Psychopharmacol. 2009 Nov;24(6):306-11.

[36] Insel TR, Murphy DL, Cohen RM, Alterman I, Kilts C, Linnoila M. Obsessive-compulsive disorder-a double-blind trial of clomipramine and clorgyline. Arch Gen Psychol 40:605-612, 1983.

[37] Geller DA, Biederman J, Stewart SE, Mullin B, Martin A, Spencer T, Faraone SV. Which SSRI? A meta-analysis of pharamacotherapy trials in pediatric obsessive-compulsive disorder. Am J Psychol 160:1919 -1928, 2003.

[38] Fineberg NA, Gale TM. Evidence-based pharmacotherapy of obsessive- compulsive disorder. Int J Neuropsychopharm 8:107-129,2005.

[39] Hollander E, Friedberg J, Wasserman S, Allen A, Birnbaum M, Koran LM. Venlafaxine in treatment-resistant obsessive-compulsive disorder. J Clin Psychol 64:972, 2003.

[40] Albert U, Aguglia E, Maina G, Bogetto F. Venlafaxine versus clomipramine in the treatment of obsessive-compulsive disorder: a preliminary single-blind, 12-week, controlled study. J Clin Psychol 63:1004 -1009, 2002.

[41] Pallanti S, Quercioli L, Bruscoli M. Response acceleration with mirtazapine augmentation of citalopram in obsessive compulsive disorder patients without comorbid depression: a pilot study. J Clin Psychol 65:1394 -1399, 2004.

[42] Schule C, Laakmann G. Mirtazapine plus citalopram has short term but not longer term benefits over citalopram alone for the symptoms of obsessive compulsive disorder. Evid Based Ment Health 8:42, 2005.

[43] Koran LM, Gamel NN, Choung HW, Smith EH, Aboujaoude EN. Mirtazapine for obsessive-compulsive disorder: an open trial followed by double-blind discontinuation. J Clin Psychol 66:515- 520, 2005.

[44] Koran LM, Faravelli CF, Pallanti S. Intravenous clomipramine in obsessive-compulsive disorder. J Clin Psychopharm 14:216 -218, 1994.

[45] Fallon BA, Liebowitz MR, Campeas R, Schneier FR, Marshall R, Davies S, Goetz D, Klein DF. Intravenous clomipramine for obsessive-compulsive disorder refractory to oral clomipramine: a placebo-controlled study. Arch Gen Psychol 55:918 -924, 1998.

[46] Pallanti S, Quercioli L, Koran LM. Citalopram intravenous infusion in resistant obsessive-compulsive disorder. J Clin Psychol 63:796-801, 2002.

[47] Stahl SM. Finding what you are not looking for: strategies for developing novel treatments in psychiatry. NeuroRx 3:000-000, 2006. 
[48] Leckman JF, Walker DE, Goodman WK, Pauls DL, Cohen DJ. "Just right" perceptions associated with compulsive behavior in Tourette's syndrome. Am J Psychol 151:675- 680, 1994.

[49] Graybiel AM, Rauch SL. Toward a neurobiology of obsessivecompulsive disorder. Neuron 28:343-347, 2000.

[50] Leckman JF, Riddle MA. Tourette's syndrome: when habit-forming systems form habits of their own? Neuron 28:349 -354, 2000.

[51] Scahill L, Leckman JF, Schultz RT, Katsovich L, Peterson BS. A placebo-controlled trial of risperidone in Tourette syndrome. Neurology 60:1130 -1135, 2003.

[52] Dion Y, Annable L, Sandor P, Chouinard G. Risperidone in the treatment of Tourette syndrome: a double-blind, placebo-controlled trial. J Clin Psychopharm 22:31-39, 2002.

[53] Savas HA, Yumru M, Ozen ME. Quetiapine and ziprasidone as adjuncts in treatment-resistant obsessive-compulsive disorder: a retrospective comparative study.. Clin Drug Investig. 2008;28:439-442.

[54] Maina G, Pessina E, Albert, Bogetto F. 8-week, single-blind, randomized trial comparing risperidone versus olanzapine augmentation of serotonin reuptake inhibitors in treatment-resistant obsessive-compulsive disorder.. Eur Neuropsychopharmacol. 2008;18:364-372.

[55] Pessina E, Albert U, Bogetto F, Maina G. Aripiprazole augmentation of serotonin reuptake inhibitors in treatment-resistant obsessive-compulsive disorder: a 12-week open-label preliminary study.. Int Clin Psychopharmacol. 2009;24:265-269.

[56] Connor KM, Payne VM, Gadde KM, Zhang W, Davidson JR. The use of aripiprazole in obsessive-compulsive disorder: preliminary observations in 8 patients.. J Clin Psychiatry. 2005;66:49-51.

[57] Otsuka T, Togo T, Sugiyama N, et al. Perspirone augmentation of paroxetine in treatment of refractory obsessive-compulsive disorder with depression.. Prog Neuropsychopharmacol Biol Psychiatry. 2007;32:564-568.

[58] Koran LM, Aboujaoude E, Bullock KD, Franz B, Gamel N, Elliot M. Double-blind treatment with oral morphine in treatment-resistant obsessive-compulsive disorder. J Clin Psychol 66:353- 359, 2005.

[59] Shapira NA, Keck PE Jr, Goldsmith TD, McConville BJ, Eis M, McElroy SL. Open-label pilot study of tramadol hydrochloride in treatment-refractory obsessive-compulsive disorder. Depress Anxiety 6:170 -173, 1997.

[60] Goldsmith TB, Shapira NA, Keck PE Jr. Rapid remission of OCD with tramadol hydrochloride. Am J Psychol 156:660-661, 1999.

[61] Hollander E, Bienstock CA, Koran LM, Pallanti S, Marazziti D, Rasmussen SA, Ravizza L, Benkelfat C, Saxena S, Greenberg BD, Sasson Y, Zohar J. Refractory obsessive- 
compulsive disorder: state-of-the-art treatment. J Clin Psychol 63 [Suppl 6]:20-29, 2002.

[62] Marazziti D, Golia F, Consoli G, et al. Effectiveness of long-term augmentation with citalopram to clomipramine in treatment-resistant OCD patients.. CNS Spectr. 2008;13:971-976.

[63] Aventis: Rilutek. In: Physician's desk reference. Montvale, NJ: Thompson Healthcare, 2004.

[64] Urbani A, Belluzzi O. Riluzole inhibits the persistent sodium current in mammalian CNS neurons. Eur J Neurosci 12:3567-3574, 2000.

[65] Wang SJ, Wang KY, Wang WC. Mechanisms underlying the riluzole inhibiton of glutamate release from rat cerebral cortex nerve terminals (synaptosomes). Neuroscience 125:191-201, 2004.

[66] Xu L, Enyeart JA, Enyeart JJ. Neuroprotective agent riluzole dramatically slows in activation of Kv1.4 potassium channels by a voltage-dependent oxidative mechanism. J Pharm Exp Ther 299:227-237, 2001.

[67] Frizzo ME, Dall'Onder LP, Dalcin KB, Souza DO. Riluzole enhances glutamate uptake in rat astrocyte cultures. Cell Mol Neurobiol 24:123-128, 2004.

[68] Coric V, Taskiran S, Pittenger C, Wasylink S, Mathalon DH, Valentine G, Saksa J, Wu YT, Gueorguieva R, Sanacora G, Malison RT, Krystal JH. Riluzole augmentation in treatmentresistant obsessive-compulsive disorder: an open-label trial. Biol Psychol 424-428, 2005.

[69] Coric V, Milanovic S, Wasylink S, Patel P, Malison R, Krystal JH. Beneficial effects of the antiglutamatergic agent riluzole in a patient diagnosed with obsessive-compulsive disorder and major depressive disorder. Psychopharm (Berl) 167:219 -220, 2003.

[70] Moran MM, McFarland K, Melendez RI, Kalivas PW, Seamans JK. Cystine/glutamate exchange regulates metabolic glutamate receptor presynaptic inhibition of excitatory transmission and vulnerability to cocaine seeking. J Neurosci 25:6389-6393, 2005.

[71] Lafleur DL, Pittenger C, Kelmendi B, Gardner T, Wasylink S, Malison RT, Sanacora G, Krystal JH, Coric V. N-acetylcysteine augmentation in serotonin reuptake inhibitor refractory obsessive-compulsive disorder. Psychopharm (Berl) 184:254-256, 2006.

[72] Pittinger C, Krystal JH, Coric V. Initial evidence of the beneficial effects of glutamate modulating agents in the treatment of self injurious behavior associated with borderline personality disorder. J Clin Psychol 66:1492-1493, 2005.

[73] Aboujaoude E, Barry JJ, Gamel N. Memantine augmentation in treatment-resistant obsessive-compulsive disorder an open label trial.. J Clin Psychopharmacol. 2009;29:51-55. 
[74] Feusner JD, Kerwin L, Saxena S, Bystritsky A, Differential efficacy of memantine for obsessive-compulsive disorder vs. generalized anxiety disorder: an open-label trial. Psychopharmacol Bull. 2009;42(1):81-93.

[75] Stewart, S. Evelyn Jenike, Eric A. Hezel, Dianne M.; Stack, Denise Egan; Dodman, Nicholas H.; Shuster, Louis; Jenike, Michael A. A Single-Blinded Case-Control Study of Memantine in Severe Obsessive-Compulsive Disorder,Journal of Clinical Psychopharmacology: February 2010 - Volume 30 - Issue 1 - pp 34-39.

[76] Greenberg WM, Benedict MM, Doerfer J, et al. Adjunctive glycine in the treatment of obsessive-compulsive disorder in adults.. J Psychiatr Res. 2009;43:664-670.

[77] Egashira N, Okuno R, Harada S, et al. Effects of glutamate-related drugs on marbleburying behavior in mice: implications for obsessive-compulsive disorder.. Eur J Pharmacol. 2008;586:164-170.

[78] Hollander E, Dell'Osso B. Topiramate plus paroxetine in treatment-resistant obsessive-compulsive disorder.. Int Clin Psychopharmacol. 2006;21:189-191.

[79] van Ameringen M, Mancini C, Patterson B, Bennett M. Topiramate augmentation in treatment-resistant obsessive-compulsive disorder: a retrospective, open-label case series.. Depress Anxiety. 2006;23:1-5.

[80] ClinicalTrials.gov Identifiers: NCT00211744 and NCT00182520.

[81] oulis P,Masdrakis VG, Karapoulios E, et al. Pregabalin augmentation to sertralinerisperidone combination in the treatment of obsessive-compulsive disorder. Prim Care Companion. J Clin Psychiatry. 2008;10:249.

[82] Roebel M, Nenadic I, Sauer H. Pregablin as a successful pharmacotherapeutic option in OCD - a case report.. Nervenarzt. 2009;80(suppl 2):P-043-007.

[83] ClinicalTrials.gov Identifier: NCT00994786.

[84] Kushner MG, Kim SW, Donahue C, et al. D-cycloserine augmented exposure therapy for obsessive-compulsive disorder.. Biol Psychiatry. 2007;15:835-838.

[85] Wilhelm S, Buhlmann U, Tolin DF, et al. Augmentation of behavior therapy with Dcycloserin for obsessive-compulsive disorder.. Am J Psychiatry. 2008;165:335-341

[86] Eric A. Storch, Tanya K. Murphy, Wayne K. Goodman, Gary R. Geffken, Adam B. Lewin, Aude Henin, Jamie A. Micco, Susan Sprich, Sabine Wilhelm, Michael Bengtson, Daniel A. Geller, A Preliminary Study of D-Cycloserine Augmentation of Cognitive-Behavioral Therapy in Pediatric Obsessive-Compulsive Disorder; Biological Psychiatry Volume 68, Issue 11, 1 December 2010, Pages 1073-1076.

[87] Fujiwara M, Egashira N: New perspectives in the studies on en- docannabinoid and cannabis: abnormal behaviors associate with CB1-receptor and development of therapeutic applica-tion. J Pharmacol Sci 2004; 96:363-366. 
[88] Pacher P, Bátkai S, Kunos G: The endocannabinoid system as an emerging target of pharmacotherapy. Pharmacol Rev 2006; 58:389-462.

[89] Improvement in Refractory Obsessive Compulsive Disorder With Dronabinol ;Am J Psychiatry 2008;165:536-537. 10.1176/appi.ajp.2007.07061016.

[90] Simpson HB, Foa EB, Liebowitz MR, Ledley DR, Huppert JD, Cahill S, Vermes D, Schmidt AB, Hembree E, Franklin M, Campeas R, Hahn CG, Petkova E.; A randomized, controlled trial of cognitive-behavioral therapy for augmenting pharmacotherapy in obsessive-compulsive disorder.; Am J Psychiatry. 2008 May;165(5):621-30. doi: 10.1176/appi.ajp.2007.07091440. Epub 2008 Mar 3.

[91] Tolin DF, Maltby N, Diefenbach GJ, Hannan SE, Worhunsky P. Cognitivebehavioral therapy for medication nonresponders with obsessive-compulsive disorder: a waitlist-controlled open trial.. J Clin Psychiatry. 2004;65:922-931.

[92] Eddy KT, Dutra L, Bradly R Westen D. A multidimensional meta-analysis of psychotherapy and pharmacotherapy for obsessive-compulsive disorder.. Clin Psychol Rev. 2004;24:1011-1030.

[93] Christopher Pittenger, John H. Krystal, and Vladimir Coric, Glutamate-Modulating Drugs as Novel Pharmacotherapeutic Agents in the Treatment of Obsessive-Compulsive Disorder: The Journal of the American Society for Experimental NeuroTherapeutics; Vol. 3, 69-81, January 2006.

[94] Nuttin B, Cosyns P, Demeulemeester H, Gybels J, Meyerson B (1999). Electrical stimulation in anterior limbs of internal capsules in patients with obsessive-compulsive disorder. Lancet 354.

[95] Nuttin BJ, Gabriels LA, Cosyns PR, Meyerson BA, Andreewitch S, Sunaert SGet al (2003b). Long-term electrical capsular stimulation in patients with obsessive-compulsive disorder. Neurosurgery 52: 1263-1272.

[96] Gabriels L, Cosyns P, Nuttin B, Demeulemeester H, Gybels J (2003). Deep brain stimulation for treatment-refractory obsessive-compulsive disorder: psychopathological and neuropsychological outcome in three cases. Acta Psychiatr Scand 107: 275-282.

[97] Abelson JL, Curtis GC, Sagher O, Albucher RC, Harrigan M, Taylor SF et al(2005). Deep brain stimulation for refractory obsessive-compulsive disorder.Biol Psychiatry 57: 510-516.

[98] Anderson D, Ahmed A (2003). Treatment of patients with intractable obsessive-compulsive disorder with anterior capsular stimulation. Case report. J Neurosurg 98: 1104-1108.

[99] Aouizerate B, Cuny E, Martin-Guehl C, Guehl D, Amieva H, Benazzouz A et al(2004). Deep brain stimulation of the ventral caudate nucleus in the treatment of obsessive-compulsive disorder and major depression. Case report. J Neurosurg 101: 682-686. 
[100] Sturm V, Lenartz D, Koulousakis A, Treuer H, Herholz K, Klein JC et al(2003). The nucleus accumbens: a target for deep brain stimulation in obsessive-compulsive- and anxiety-disorders. J Chem Neuroanat 26: 293-299.

[101] Aouizerate B, Martin-Guehl C, Cuny E, Guehl D, Amieva H, Benazzouz A et al(2005). Deep brain stimulation for OCD and major depression. Am J Psychiatry 162: 2192.

[102] Benjamin D Greenberg, Donald A Malone, Gerhard M Friehs,et al; Three-Year Outcomes in Deep Brain Stimulation for Highly Resistant Obsessive-Compulsive Disorder; Neuropsychopharmacology (2006) 31, 2384-2393. doi:10.1038/sj.npp.1301165; published online 19 July 2006.

[103] Maletzky B, McFarland B, Burt A. Refractory obsessive compulsive disorder and ECT. Convuls Ther. 1994;10:34-42.

[104] Thomas SG, Kellner CH. Remission of major depression and obsessiveCompulsive disorder after a single unilateral ECT. J ECT. 2003;19:50-51.

[105] Lavin MR, Halligan P. ECT for obsessive-compulsive disorder and schizophrenia. Am J Psychiatry. 1996;153:1652-1653.

[106] Casey DA, Davis MH. Obsessive-compulsive disorder responsive to electroconvulsive therapy in an elderly woman. South Med J. 1994;87:862-864

[107] Mellman LA, Gorman JM. Successful treatment of obsessive-compulsive disorder with ECT. Am J Psychiatry. 1984;141:596-597.

[108] Strassnig M, Riedel M, Muller N. Electroconvulsive therapy in a patient with Tourette's syndrome and co-morbid obsessive compulsive disorder. World J Biol Psychiatry. 2004;5:164-166.

[109] Greenberg BD, George MS, Martin JD, et al. Effect of prefrontal repetitive transcranial magnetic stimulation in obsessive-compulsive disorder: a preliminary study. Am J Psychiatry. 1997;154:867-869.

[110] Sachdev PS, McBride R, Loo CK, Mitchell PB, Malhi GS, Croker VM. Right versus left prefrontal transcranial magnetic stimulation for obsessive-compulsive disorder: a preliminary investigation. J Clin Psychiatry. 2001;62:981-984.

[111] Mantovani A, Lisanby SH, Pieraccini F, et al. Repetitive transcranial magnetic stimulation (rTMS) in the treatment of obsessive-compulsive disorder (OCD) and Tourette's syndrome (TS). Int J Neuropsychoph. 2005 Jun 28;1-6.

[112] Chiara Ruffini, Marco Locatelli,, Adelio Lucca, Augmentation Effect of Repetitive Transcranial Magnetic Stimulation Over the Orbitofrontal Cortex in Drug-Resistant Obsessive-Compulsive Disorder Patients: A Controlled Investigation Prim Care Companion J Clin Psychiatry. 2009; 11(5): 226-230.

[113] Antonio Mantovani, Helen B. Simpson, Brian A. Fallon, Simone Rossi and Sarah H. Lisanby Randomized sham-controlled trial of repetitive transcranial magnetic stimu- 
lation in treatment-resistant obsessive-compulsive disorder The International Journal of Neuropsychopharmacology / Volume 13 / Issue 02 /March 2010, pp 217-227.

[114] Umberto Albert, Andrea Aguglia, Stefano Bramante, Filippo Bogetto, Giuseppe Maina: TREATMENT RESISTANT OBSESSIVE COMPULSIVE DISORDER(OCD): CURRENT KNOWLEDGE AND OPEN QUESTIONS:Clinical Neuropsychiatry (2013) 10,1,19-30.

[115] Denys D, Van Nieuwerburgh F, Deforce D, Westenberg HG. Prediction of response to paroxetine and venlafaxine by serotonin-related genes in obsessive-compulsive disorder in a randomized, double-blind trial.J Clin Psychiatry. 2007 May;68(5):747-53.

[116] Saxena S, Brody AL, Ho ML, Zohrabi N, Maidment KM, Baxter LR Jr. Differential brain metabolic predictors of response to paroxetine in obsessive-compulsive disorder versus major depression. Am J Psychiatry. 2003 Mar;160(3):522-32.

[117] Edwards, I., Isaac, M., Johansson, M., Malmberg, J., Mindis, A.,Staaf, K., Slassi, A., Wensbo, D.: WO05080379A1 (2005).

[118] Bryan C, Isaac M, Stefanac T: WO05080363A1 (2005).

[119] Johansson, M., Wensbo, D., Mindis, A., Staaf, K., Edwards, L., Isaac, M., Stefanac, T., Slassi, A., McLeod, D.: WO05080397A2(2005). 
